\title{
Symbolic, Aesthetic and Generative Applications
}

\author{
Michael J. Ostwald ${ }^{1}$
}

Published online: 25 June 2015

(C) Kim Williams Books, Turin 2015

\begin{abstract}
Co-Editor-in-Chief of the Nexus Network Journal, Michael J. Ostwald, introduces 16 papers in vol. 17, no 2 (2015).
\end{abstract}

In a chapter in our recent edited book, Kim Williams and I set out to classify the different types of relationships between architecture and mathematics that we have observed in the almost 20 year history of the Nexus conference series and the Nexus Network Journal. As part of this process we identified three overarching categories that capture the majority of the ways mathematics is used in the service of architecture (Ostwald and Williams 2015). The first of these categories is "mathematics for architecture", being practical or functional tools or techniques for the support of architectural design, construction and conservation. The second is "mathematics in architecture", encompassing geometric or numeric properties that are demonstrated or visible in a design. The final category is the "mathematics of architecture", which includes logical and analytical methods for quantifying various properties of space and form. Within these three overarching categories, there are 12 subsets or application types. For example, one of these application types is "measurement", which is defined as "the use of mathematics to record and communicate dimensional information" (Ostwald and Williams 2015, p. 46). Another application is, "inspiration", the use of mathematics as "an influence, motivation or means of animation" (Ostwald and Williams 2015, p. 46). While not necessarily exhaustive, this multi-level, multi-factor system was developed to support scholars to clarify their own thinking when they are interrogating particular connections between architecture and mathematics.

The research featured in vol. 17, no 2 of the Nexus Network Journal: Architecture and Mathematics, covers at least six of the 12 application types,

Michael J. Ostwald

Michael.Ostwald@newcastle.edu.au

1 The University of Newcastle, Callaghan, NSW 2308, Australia 
although the vast majority of the papers are concerned with just three of these. The most common application types found in this issue are "symbolic" and "aesthetic". The first of these involves the use of mathematics to represent or communicate something about a building. The second covers applications of mathematics to achieve a particular appearance or visual effect. More than half of the papers in this issue examine the ways architects have used geometry for symbolic of aesthetic purposes. The third most common application type in this issue is "generation", being the use of rules or algorithms to evolve or parameterise aspects of a design. While other themes are present in the papers that make up vol. 17, no 2, symbolic, aesthetic and generative applications dominate the issue.

In the first paper in this issue, Antonio César González-García and Juan Antonio Belmonte, examine the orientation of Pre-Romanesque Churches in the Iberian Peninsula. Using a statistical analysis of 167 churches that were built prior to 1086 AD, González-García's and Belmonte's results confirm the anticipated pattern wherein the orientation of the apse reflects the equinox, but within this larger trend, various unexpected patterns emerge. The second paper in this issue, by Patricia Benítez Hernández and Mercedes Valiente López, is about the geometrical properties of Late Gothic helical stairs. In the late fifteenth century the geometry of the spiral staircase had to serve both practical (structural) and aesthetic (proportional) purposes. Benítez Hernández and Valiente López identify two types of geometric constructions for these stairs-the "radial solution" and "tangent solution" - and compare their applications and outcomes. The geometric constructions found within sixteenth-century fortifications are the subject of the next paper, by Silvia Bertacchi and Sandro Parrinello. Italian military engineer Giovanni Battista Antonelli wrote an important treatise on this topic, the Epitomi delle fortificationi moderne, in the mid sixteenth century. In their research, Bertacchi and Parrinello investigate Antonelli's treatise, focussing on geometrical properties, both proportional and defensive. The geometry of Baroque oval-plan churches is the topic of the fourth paper in this issue. In this research Sylvie Duvernoy examines a series of oval plan, late Cinquecento, churches and domes, noting that while the oval geometry seemingly accommodated both symbolic and pragmatic requirements at the time, it also posed a challenge for architects to resolve. The following paper, by Liz Dewitte, is about proportional systems in the architecture of Benedictine monk Dom Paul Bellot. Dewitte's paper undertakes a close review of the geometrical properties of the Augustinian College in Eindhoven, built by Dom Bellot between 1922 and 1925. Through this review Dewitte uncovers a recurring geometric system that has been used to sub-divide and order different parts of the building to achieve a harmonious composition. The next paper, by Marco Giorgio Bevilacqua, examines the helical structures and planning used by architect Vittorio Bonadè Bottino. While best known for his Lingotto factory in Turin, in the 1930s Bonadè Bottino also produced helical towers in Sestrière, Marina di Massa and Sauze d'Oulx. Bevilacqua investigates three of these designs, not only in terms of their planning and structure, but also their symbolic properties.

The next two papers are about proportions, geometry and representation. In the first, Vitor Murtinho offers a new interpretation of Leonardo da Vinci's illustration of Vitruvian Man. Several established explanations for Leonardo's famous 
geometric tracery on the human body are derived from golden ratio constructions. However, in this paper Murtinho notes the geometric inconsistencies which are implicit in these arguments and suggests an alternative construction for Vitruvian Man. In contrast, Ufuk Soyöz's research is concerned with the way in which geometric corrections or distortions of form have been employed to achieve different optical outcomes. The paper argues that rather than being used to clarify the perception of architectural form, optical correction techniques were often used to achieve complex spatial illusions.

The next two papers in the issue shift the focus to the use of mathematics and science as a means of systematising knowledge and in doing so, understand various aspects of architecture, perception and culture. In particular, in the first of these, Michela Rossi and Giorgio Buratti examine the geometric systems used to classify or understand colour. Throughout history, various geometric models have been employed to represent and explain the differences between colours. By tracing the history of these models, Rossi and Buratti identify the role played by geometry as an ordering system with both practical and symbolic properties, before considering a new parametric model of colour classification. In the next paper Maria Zack examines the reconstruction of two cities and the mathematical and scientific models and methods_-once again, both practical and symbolic_-which separately underpinned the rebuilding efforts. The two cities are London, which was decimated by fire in 1666, and Lisbon, which was extensively damaged by an earthquake in 1755.

The final three papers in the research section of the issue look at specific dimensional and geometric theories and techniques. Snezana Lawrence's paper, "Life, Architecture, Mathematics and the Fourth Dimension" traces the history of architectural interest in the fourth dimension, examining the social, ethical and theological forces which inspired architects to look beyond conventional two and three-dimensional forms. Cylindrical mirror anamorphosis is the topic of the paper from Marijana Paunovic and Aleksandar Čučaković. Anamorphosis is the conceptualisation and realisation of an image that can only be viewed in its correct proportions, from a specific location. Mirror anamorphosis involves the use of optical geometry (projections and reflections) to realise the construction of such an image. The next paper, by Mauro Chiarella and Rodrigo García Alvarado, examines the spatial and material properties of folds. Using a combination of constructed and unbuilt examples, from architectural practices, academics and students, this paper describes the parametric modelling, digital fabrication and assembly of folded compositions.

The Didactics section of the journal is for papers that have an overt educational agenda or focus and the Geometer's Angle section is dedicated to explorations and explanations of geometric constructions. The Didactics section of this issue includes two papers, both from Authors at the Middle East Technical University (METU) in Ankara (Turkey). The paper by Arzu Gönenç Sorguç, demonstrates an application of computational design in studio education. Using rule-based and parametric models, the paper explores several design and visualisation studies involving the mapping of movement. The following paper, by Firat Özgenel and Arzu Gönenç Sorguç, describes a new way of modelling complex reflected rays in three- 
dimensional space. In the Geometer's Angle, Javier Barrallo, Francisco GonzálezQuintial and Santiago Sánchez-Beitia provide an introduction to the history and geometric properties of the Vesica Piscis and the Reuleaux Triangle. Their paper concludes with a series of examples of applications of related geometric structures in architecture.

There are two book reviews in this issue, the first of which is Elena Marchetti's review of Viewpoints: Mathematical Perspective and Fractal Geometry in Art by Marc Frantz and Annalisa Crannel. The second is Sylvie Duvernoy's review of Rachel Fletcher's Infinite Measure: Learning to Design in Geometric Harmony with Art, Architecture and Nature. Fletcher's research will be well known to readers of the Nexus Network Journal, through her longstanding involvement in the Geometer's Angle.

Finally, several of the papers in this issue were originally presented at the Nexus, Architecture and Mathematics Conference in Ankara, Turkey, in 2014. These papers not only went through a rigorous double-blind-refereeing process prior to acceptance and presentation, but they also benefited from discussions that occurred during the conference, and from a second round of reviews after the event. The remainder of the papers came through the conventional journal process, doubleblind refereeing by experts.

\section{Reference}

Ostwald, Michael J., and Kim Williams. 2015. Mathematics in, of and for Architecture: A Framework of Types. In: Architecture and Mathematics, From Antiquity to the Future. eds. Kim Williams and Michael J. Ostwald, Vol. I. 31-57. Cham: Springer.

Michael J. Ostwald is Professor and Dean of Architecture at the University of Newcastle, Australia. He is a Visiting Professor at RMIT University and a Research Fellow at SIAL (Melbourne). Michael has a $\mathrm{PhD}$ in architectural theory and history and a higher doctorate (DSc) in design mathematics. He is coeditor-in-chief of the Nexus Network Journal: Architecture and Mathematics (Springer) and on the Editorial Board of $A R Q$ (Cambridge) and Architectural Theory Review (Taylor \& Francis). His latest book, coedited with Kim Williams, is the two volume Architecture and Mathematics from Antiquity to the Future (Springer 2015). 